\title{
Identidade e Alteridade - o legado de Paul Ricoeur
}

Alex Villas Boas*

questão hermenêutica emerge da refundação ontológica do Ocidente, da questão da "essência" das coisas, para uma outra forma de pergunta essencial, que redirecionando o foco da contemplação do Ser, adentrando a um modo de ser, em uma mudança de época, que se via ameaçado por sua confusa percepção de si, o humano.

Naturalmente, portanto, o cogito humano desloca o acento de atenção em entender as coisas, para se entender diante das coisas, o que implicava em revisitar a tradição filosófica e também teológica, tarefa essa que exige revisitar a questão do sentido [logos] do ser [ontos] para compreender o sentido do humano, e sua tarefa de humanizar-se.

A consciência hermenêutica tem sua 
consumação na comunidade de experiência que integra as perguntas de hoje, que podem não se identificar com a insuficiência das respostas de outra época, sem contudo ser necessário rejeitar as perguntas da tradição do pensamento que podem ampliar, inclusive, o campo polissêmico do efeito de sentido da busca. Desconsiderar a historicidada da finitude em nome da objetividade é simples dogmatismo ${ }^{1}$. Por outro lado, também a subjetividade precisa ser depurada dos pré-conceitos que carrega, e estes mais ainda constituem sua realidade histórica, pois carregam as marcas da história. Para lembrar Gadamer, companheiro de busca de Ricoeur ${ }^{2}$ :

\begin{abstract}
"a interiorização das "vivências", não pôde construir a ponte para as realidades histórias, porque as grandes realidades históricas, sociedade e Estado, determinam de antemão toda a "vivência". A auto-reflexão e a autobiografia - pontos de partida para Dilthey - não são fatos primários e não bastam como base para o problema hermenêutico, porque por elas a história é reprivatizada. Na verdade, não é a história que nos pertence, mas somos nós que pertencemos a ela. (...) a lente da subjetividade é um espelho deformante. A auto-reflexão do indivíduo não passa de uma luz tênue na corrente cerrada da vida histórica. Por isso, os preconceitos de um indivíduo, muito mais que seus juízos, constituem a realidade histórica de seu ser".
\end{abstract}

A tradição, na medida em que é uma tradição hermenêutica, permite tomar consciência dos pré-conceitos na medida em que se recupera nela suas perguntas, mais que suas respostas, pois está precisa ser dada no "ai" do tempo presente. Gadamer parte da insustentabilidade da ideia de conhecimento universalmente válido, de uma verdade absoluta que poderia ser generalizada a partir de uma experiência particular e histórica, ou seja, de uma formulação definitiva da verdade. Na medida em que se recupera as experiências que formaram as perguntas da tradição

1. GADAMER, Hans-Georg. Verdade e Método - traços fundamentais de uma hermenêutica filosófica. Petrópolis: Editora Vozes/Bragança Paulista: EDUSF, 2005, p. 472 2. GADAMER, Hans-Georg. Hermenêutica em Retrospectiva. Petrópolis: Editora Vozes, 2007, p. 367-368. 
é que se toma consciência das próprias experiências que formulam a pergunta. A resposta só é possível como experiência hermenêutica em busca de um sentido. $E$ entre as experiências que podem provocar o efeito do sentido a arte é aquela que nos fala de "modo mais imediato" em uma "familiaridade enigmática" de como o encontro com a "obra de arte" é sentido como se fosse um "encontro com nós mesmos", pois a hermenêutica "contém a estética" ${ }^{4}$ :

"a experiência da arte que precisamos fixar contra a nivelação da consciência estética consiste justamente em que a obra de arte não é um objeto que se posta frente ao sujeito que é por si. Antes, a obra de arte ganha seu verdadeiro ser ao se tornar uma experiência que transforma aquele que a experimenta".

Assim em Gadamer a mimésis ocupa um lugar central em Verdade e Método, vinculando-a uma ontologia geral aplicada a arte, o que poderia se dizer de uma ontologia da arte, a partir da categoria do jogo que ocorre entre o mundo real e o mundo da obra, como autorepresentação.

Para o filósofo alemão, a representação é a manifestação do que antes não "era" e que passa a ser desde que emergindo da arte. Em Gadamer mimésis é poiésis. A autorepresentação é a representação do mundo da obra, na medida em que abre o mundo da ficção, um mundo próprio porque com sentido próprio constituindo uma unidade de sentido, e a princípio fechado em si mas suscetível de ser compreendido e interpretado, porém não por parâmetros externos, a não ser a do mundo da obra, apesar da biografia do autor e do mundo real no qual nasce a obra.

A verdade do texto, portanto, não se verifica em dados empíricos da realidade, mas sim em sua pertinência e congruência dentro de sua unidade de sentido que provoca verossimilhança, de modo que não é somente a poesia criada mas criadora de verdade, ou seja, de sentido. $\mathrm{O}$

3. Ibidem, p. 22

4. Ibidem, p. 155. 
papel da poesia, em sentido amplo, como literatura é proeminente frente às outras artes, segundo Gadamer, porque o texto se faz existir através das palavras e esta constitui o lugar priveligiado que permite acessoa-representação-do-ser, enquanto "cria" um sentido que desvela o ser fazendo "algo" ser "ai". A mimesis é que vincula o mundo da ficção com o mundo real e da à realidade uma nova abertura de sentido, configurando a realidade de outro modo a partir do momento que é nomeada pelo mundo da ficção. Não é mais mera constatação, mas é parte de uma obra que convida a descobrir o sentido que está "ai" como "algo" próprio. A re-presentação do mundo na obra permite uma identificação, um "reconhecimento" experiênciado como "crescente familiaridade", onde se faz mais profundo o "conhecimento de si" descobrindo novas relações de "familiaridade com o mundo". A descoberta de uma nova forma de se relacionar é descobrir um novo modo de ser. A poesia para Gadamer assim é um "testemunho de ordem" de modo que constroe e ordena o mundo, dando-Ihe sentido e configurando-o. Não ordena com leis e fundamentos, como é perspectiva científica, mas pela sua capacidade de colocar as coisas em circunstâncias que as iluminam, desvelando-as, e criando um universo de sentido como um mundo humano.

A poesia é propriamente hermenêutica, herança viva e re-significadora da tradição, pois a obra de arte não se limita a uma interpretação, mas se apresenta como um permanente ler que jamais a deixa lida. O objeto literário permanece inesgotável diálogo aberto com o passado rumo ao futuro de um novo presente. A compreensão do texto é sua execução, efeito do acontecimento revelacional da obra literárias:

"é incontestável que a arte jamais é passado, mas consegue superar a distancia dos tempos através da presença do seu próprio sentido. Assim, parece que a partir de um duplo ponto de vista o exemplo da arte nos mostra um caso privilegiado de compreensão. $A$ arte não é mero objeto da consciência histórica e, no entanto a sua compreensão implica sempre uma mediação histórica.

5. Ibidem, p. 232-233. 
[...] se sabemos e reconhecemos que a obra de arte não é um objeto a-temporal da vivência estética, mas pertence a um mundo e somente este poderá determinar plenamente o seu significado, parece que devemos concluir que o verdadeiro significado da obra de arte só pode ser compreendido a partir desse "mundo", portanto, principalmente a partir de sua origem e de seu surgimento".

O edifício teórico de Gadamer de recuperar a tradição do pensamento ontológico permaneceu suspeito aos olhos da "neomodernidade", desconfiada das tradições, devido ao uso abusivo das instituições que apelavam para um autoritarismo radicado nas origens históricas das mesmas que atravessavam o tempo. A busca por resignificar a tradição e sua pertinência esbarra na percepção de que ela é mera repetição de respostas que legitimam as posturas políticas contemporâneas, e consequentemente a ideia de novo para ganhar o status de adjetivo. A percepção do mundo que emerge de si é inegociável ao indivíduo contemporâneo, intolerante a qualquer forma de autoritarismo, desde as quatro paredes do lar em sua idade mais tenra até os regimes políticos, e qualquer aceno que recorra a autoridade da história, resulta em desconfiança da propaganda historiografica. No entanto, um olhar mais atento pode reabilitar a história e apreender com a história no modo de responder seus desafios, mais que exatamente com as respostas que se deu, e portanto, com a tradição do pensamento, mais que com as afirmações e posições históricas das instituições que também faziam uso das mesmas tradições. Agostinho é um exemplo concreto da possibilidade sincrônica do pensamento. Lido obrigatoriamente pela Patrística volta a ser lido atentamente pelos escolásticos, tanto pela escolástica católica quanto pela escolástica protestante, torna a ser lido para refundar um agostinianismo político, quase que ao mesmo tempo em que se Ihe é emprestado, não sem licença filosófica, seu cogito para refundar a epistemologia cartesiana, bem como inesperadamente é revisitado na formulação da reflexão existencial em Kierkegaard, que a partir dai será lido por Heidegger, não sem um pedágio obrigatório do nihilismo niet- 
zchiano e que desembocará em uma bifurcação da leitura do corpus agostinianum, enveredando por um lado pelo existencialismo teísta de Jaspers, Frankl, K. Rahner, Simone Weill entre tantos mais e por outro lado por sua versão não teísta, como Schopenhauer, Sartre, Camus, Hannah Arendt sem contar a influência no giro linguístico do pensamento desde Wittengenstein até Pierce, Saussure e Perelmann. Agostinho é a evidência mais clara de como a tradição pode oferecer luz para a inspiração de novas investidas hermenêuticas. Todavia, há que se atentar para o fato de que essa certa exigência do corpus agostinianum não se dá em forma de obrigatoriedade como tempos de escolástica, mas sim pela pertinência da sua profundidade. Heidegger rele as Confissões ${ }^{6}$ em uma perspectiva fenomenológica, e evidencia a capacidade de "narrar as imagens" da memória, lugar em que residem os afetos vitais da apreensão de sentido. A imaginação, na modernidade, fora relegada à louca da casa com Descartes por julgar ser ela fruto das paixões da alma ${ }^{7} \mathrm{e}$ sendo assim, digna de ser combatida, devido à imagem estar separada do pensamento empírico e conceitual, resultando na tentativa de um método positivo para o entendimento do "eu" a partir da imagem, como "ideia confusa" a ser esclarecida pela razão, e por isso a literatura no positivismo de Hippolyte Tayne é um "appareil"8, um dispositivo social para medir os graus e variações da sociedade, de modo que a imaginação literária é um retrato social, porque capta a variação subjetiva das estruturas objetivas. Percepção essa que Freud transpõe para sua teoria a partir da tragédia grega como retrato adequado da objetividade das leis de funcionamento do inconsciente e sua imaginação subjetiva fantasiosa. A literatura é uma imaginação da imanência, não raro demente, que

6. HEIDEGGER, Martin. Fenomenologia da Vida Religiosa. Col. Pensamento Humano. Petrópolis: Editora Vozes/Bragança Paulista: Editora Universitária São Francisco, 2010, 165 apud Confessionum X,8,12.

7. DESCARTES, René. Méditations et Principes. In: Oeuvres de Descartes. Paris: Librairie Philosophique J. Vrin, 1996, p. 22; . Les Passions de L'Âme. Paris: Vrin, 1970.

8. HIPPOLYTE, Taine. Die Entstehung des modernen Frankreich. Tradução do Original "Les Origines de la France contemporaine" por Katscher Leopold. Berlin ; Frankfurt a.M. : G. B. Fischer, 1954. 
procura fugir do princípio de realidade.

Contudo, a imaginação no pensamento de Agostinho também foi

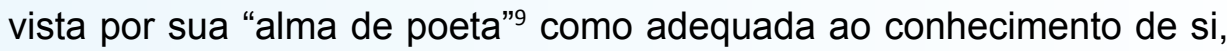
não somente para melhor aceitação do super ego e adequação social, mas como capaz de transcendência e da descoberta de sentido que formule uma identidade em um novo projeto de si em uma nova compreensão das possibilidades, ou seja, se a consciência ontológica emerge da linguagem, ela pode ser melhor articulada pela Literatura, enquanto a imaginação permite "visualizar" não somente o imaginário social da realidade, ou uma fantasia como fuga da realidade, mas também e mais ainda, um vir-a-ser que advém da percepção de um sentido mais profundo do existir, pela manifestação da beleza do Ser, e aqui advêm a grande contribuição de Paul Ricoeur. Assim como Gadamer, filósofo francês continua a busca de uma filosofia hermenêutica, contudo em diálogo com a Teoria Literária, também se atém ao texto narrativo por sua capacidade de descrever a realidade, mas também por sua capacidade de reconfiguração do mundo do leitor e como constituição da identidade pessoal levando o texto ao mundo da práxis, pois as obras de arte, de modo especial as de linguagem, emergem da vida e a ela pertencem.

Deste modo, Ricoeur a partir da Poética de Aristóteles se apropria de suas categorias centrais de Poiésis, Mímesis e Catharsis e desdobrará o conceito de mímesis. Em Aristóteles a poiésis da linguagem procede da íntima relação entre mythos e mímesis, ou seja, a linguagem só cria representando, e ao representar o faz de modo diferente, e eis a criação. A mímesis em Ricoeur é o que permite vincular o texto com a realidade.

A mímesis ricoeuriana faz do texto uma mímesis do mundo e se desdobra em três mímesis I, II e III a partir da Poética de Aristóteles, a

9. Grenier julga que há uma grande influência de Gregório de Nazianzo, teólogo e poeta capadócio do século IV no pensamento de Agostinho sobretudo na Carmina gregoriana sobre a vita sua e as Confissões do pensador de Hipona. GRENIER, A. La Vie et le Poésies de Saint Gregoire de Nazianze. Clemont-Ferrand: Typographie de Paul Huber: 1858, pp. 236-243. 
saber: o mundo da práxis, o texto da obra e o espectador. A Mímesis / diz respeito então a narrativa, ao mundo em que se desdobra a existência ou a visão de mundo de onde surge a Mímesis II, ou seja o relato. $O$ texto fala da realidade, porém ao dizer a redescreve no mythos, isto é, na trama que é mímesis praxeos. A relação essencial entre mythos e mímesis é constituída pela criação daquele, de modo que um não existe sem o outro. Por fim, a Mímesis III constitui para Ricoeur o elemento aristotélico da catharsis provocada pelo texto, ou seja, da refiguração que o texto provoca no leitor, por meio de sua configuração narrativa da realidade no mundo da obra, alterando a sua pré-figuração ${ }^{10}$. E sua capacidade de produzir a ação no mundo que faz da poiesis uma metáfora viva na medida em que o leitor acolhe o sentido da obra em sua subjetividade e historicidade. A Mímesis III está em sintonia com o conceito de Gadamer de fusão de horizontes, na intersecção do mundo do texto e o mundo do leitor é que a metáfora é viva. A leitura é uma busca de sentido e o texto provoca uma ação significativa ${ }^{11}$

O traço fundamental do mythos é sua capacidade de ordem, de organização pois ao retratar o mundo assim o faz configurando a trama do mythos e assim o faz processualmente clarificando e dando sentido às ações que vão encontrando uma ordem, uma teleologia, enquanto finalidade. Assim o desenrolar da trama se dá em uma dialética de criação e descobrimento, de modo que a mímesis é poiésis que presente no mythos a "põe diante dos olhos" uma outra ordem que não era possível vislumbrar na vida real. Poiésis é a combinação essencial de mímesis e mythos que provoca transformação, desvio e trangressão da realidade pois "diz de outro modo". Este dizer é composto de quatro elementos: 1) Ordem como sequência e estabelecimento de relações entre os acontecimentos; 2) Sentido como explicação e clarificação dos acontecimentos; 3) Metáfora como atribuição impertinente que redescreve a realidade por percepção do semelhante, não presente na cotidianidade,

10. Equivale ao "pré-conceito" em Gadamer.

11. De texto a acción, p. 169ss. 
e; 4) Ficção, como abertura de mundos possíveis, existências possíveis graças às variações imaginativas. Assim a imitação é duplamente e ao mesmo tempo "um quadro do humano e uma criação original". A poesia é para Ricoeur um poder de "detecção ontológica". Nenhum discurso pode suprimir nossa pertença ao mundo, nem mesmo a ficção, que sequer tem essa pretenção, senão a de encontrar um sentido mais claro da existência que possa recriar o mundo.

A ação significativa, enquanto ação consciente precisa passar por uma poética da vontade dando a esta uma inovação semântica, característica do uso metafórico da linguagem como re-significado da real vontade de sentido"12. O efeito de sentido em Gadamer é visto como "efeito de referência" o sentido está em referência a realidade, e o efeito de referência produzido pela ficção diz respeito ao poder de "reescrever a realidade", de uma outra realidade possível ${ }^{13}$. Este efeito resultante do diálogo com o texto é que permite ser afetado pelo texto, autocompreender-se e projetar um mundo possível. Contudo, para que o fatídico nos afete de modo a provocar a utopia, é preciso vislumbrar pela imaginação da ficção, que amplia a capacidade de ser afetado pela realidade ${ }^{14}$ :

"Ficamos afetados pelos efeitos da história somente na medida em que somos capazes de ampliar nossa capacidade de ser afetados. A imaginação é o segredo desta competência".

Compete a imaginação ficcional reverter o efeito "antagônico e semipatológico" do imaginário social, repolarizando da negatividade destrutiva para a inventividade construtora, da ideologia para a utopia como "projeto imaginário de outra sociedade, de outra realidade" texto se desdobra em ação ética que por sua vez se desdobra em cons-

12. De texto, p. $197-198$

13. De texto, p. 204.

14. De texto, p. 210.

15. Idem, p. 213. 
ciência política que "transfome a vida"16 17 .

"o conceito de mímesis [...] nos recorda que nenhum discurso pode suprimir nossa pertença a um mundo. Toda mímesis, inclusive criativa, sobretudo criativa, se situa no horizonte de um ser no mundo ao que ela faz presente na medida mesma em que o eleva a mythos. A verdade do imaginario, o poder de detecção ontológica da poesia".

Em suma, se Gadamer enfatiza a pertença a tradição para superação dos pré-conceitos no discurso [Sprachlichkeit], Ricoeur enfatiza o distanciamento, sobretudo quando o discurso se torna texto narrativo [Schriftlichkeit], pois enquanto texto, seu significado não pertence nem ao autor, nem ao leitor. Contudo, não necessariamente este refuta aquele, apenas no que o primeiro conclui, o segundo vê como ponto de parti$\mathrm{da}^{18}$. Eis Ricoeur, um novo ponto de partida, que implica um olhar sobre o olhar que temos da realidade, sobretudo, o olhar que é capaz de enxergar o outro como tarefa filosófica, exigindo uma exigente autocrítica.

Os artigos desta edição dedicada ao ilustre filósofo estão longe de esgotar a profundidade do seu pensamento e seus incontáveis desdobramentos. Antes, são testemunhas de sua fecundidade e lucidez, como é o primeiro artigo, de Marie-France Begué, da Universidad del Salvador, Argentina e fundadora do Fonds Ricoeur na França e sua representação latino americana, com inegável conhecimento do pensamento de Paul Ricoeur, orientador de sua tese doutoral, trabalhando a fulcral questão da Simbólica do Mal para o divisor de águas da Escolástica para a Modernidade.

16. DEtexto, p. 373.

17. Metáfora viva, p. 65

18. "É a partir desse conceito da eficiência histórica que gostaria de colocar meu próprio problema: como é possível introduzir qualquer instância crítica numa consciência de pertença expressamente definida pela recusa do distanciamento? A meu ver, isso só pode ocorrer na medida em que essa consciência histórica não se limitar a repudiar o distanciamento, mas de forma a também empenhar-se em assumi-lo. A este respeito, a hermenêutica de Gadamer contém uma série de sugestões decisivas que se tornarão o ponto de partida de minha própria reflexão, no segundo estudo".cf. RICOEUR, Paul. Interpretação e Ideologias, 1977. 
O segundo artigo, de Geraldo de Mori, da Faculdade de Filosofia e Teologia dos Jesuítas (FAJE) e vice-presidente da Sociedade Brasileira de Teologia e Ciências da Religião (SOTER), a respeito da teoria do texto e da narração em Paul Ricoeur, aplicadas à obra Viva o Povo Brasileiro de João Ubaldo Ribeiro, relação inédita e expressiva do instrumental ricoeuriano para o diálogo literatura e teologia, em que há uma narratividade como exercício de transcendência.

O terceiro artigo, de Alessandro Rocha, pesquisador da Catedra UNESCO de Leitura, da continuidade aos dois, levantando a questão da hercúlea e tarefa de nomear [o inominável] Deus, resgatando à categoria Deus o direito de Mistério, tarefa impossível pelo fato do contingente não abarcar o incontido e ao mesmo tempo radicalmente necessário, como exercício de busca de sentido.

O quarto artigo, de Alessandra Viegas, da Pontifícia Universidade Católica do Rio de Janeiro (PUC-Rio), não permite que um olhar mais desavisado julgue que o pensamento ricoeuriano seja tido como pura abstração, mas antes faz jus à virtude do grande pensador de vincular o texto à vida, e mais ainda à consciência que se tem em relação no tecido vital e social.

O quinto artigo, de Leandro Garcia Rodrigues, diretor de pesquisa do Colégio Naval da Marinha Brasileira, desvela a relação entre o registro literário e a experiência de sentido, entre o Exxtase e a Escrita em no Diário Íntimo de Santa Teresa de los Andes.

O sexto artigo, de Lucas Adur, da Universidad de Buenos Aires (UBA) e Premio Academia Argentina de Letras ao melhor promedio (2008), apresenta o Escandâlo da Razão que a relação teologia e literatura estabelecem à conceituação histórica de Deus, sobretudo da Escolástica decadente, pela pena do assim chamado "teólogo ateu" que diz Deus as avessas, Jorge Luiz Borges.

O sétimo artigo, de Luciano Santos, Universidade Estadual da Bahia (UEBA) mostra como a experiência de sentido, nomeada experi- 
ência de Deus se esconde na experiência estética de inúmeros escritores de inspiração cristã, resultando na apropriação criativa da expressão da fé - ousar crer, ousar criar -, de acordo com as necessidades da mudança de época.

O oitavo artigo, de Raphael Novaresi Leopoldo, da Universidade Federal d Santa Catarina (UFSC) apresenta um instigante e original trabalho da relação entre ficção e realidade, na medida em que engedra um aprofundamento da realidade de um ordem religiosa factual [beneditina] na imagem de uma ordem religiosa ficcional [castáltica] em Jogo das Contas de Vidro de Hermann Hesse.

Como filosofia da Teoliteraria, pretendemos divulgar a pesquisa e estreitar cada vez mais os laços entre Literatura e Teologia, sendo assim, também um espaço de fomento à iniciativa, divulgando não somente as pesquisas de ponta, mas também as iniciais, como é a nota bibliográfica do trabalho monográfico de Renato Gomes Alves na Pontifícia Universidade Católica de São Paulo (PUC-SP) em que apresenta Brás Cubas de Machado de Assis, como um indivíduo sem sentido em busca de sentido.

Por fim, indicamos três obras inéditas e significativas para a pesquisa na área, a saber 1) Teologia y Literatura do chileno Alberto Toutin, apresentada por Antonio Manzatto, vice-presidente da ALALITE, como uma leitura obrigatória; 2) Aragem do Sagrado - Deus na literatura contemporânea brasileira, obra que reúne o resultado de pesquisas de vários teólogos e críticos de literatura ampliando o leque de possibilidades desse horizonte de pesquisa, com posfácio de Karl-Joseph Küschel, apresentado por Geraldo de Mori, um dos organizadores do trabalho; e, 3) uma obra de Schelling apresentando a estética como uma rota para a "aventura" enigmática a partir aforismos, por Marcelo de Souza Will, da Universidade Federal Fluminense (UFF).

Desejamos ao leitor desta edição da Teoliteraria que possa não somente compreender os textos, mas se compreender diante dos textos! 